\title{
Recent fluctuations of meteorological and snow conditions in Japanese mountains
}

\author{
Satoru YAMAGUCHI, ${ }^{1}$ Osamu ABE, ${ }^{2}$ Sento NAKAI, ${ }^{1}$ Atsushi SATO ${ }^{1}$ \\ ${ }^{1}$ Snow and Ice Research Center, National Research Institute for Earth Science and Disaster Prevention (NIED), Suyoshi-machi, \\ Nagaoka 940-0821, Japan \\ E-mail: yamasan@bosai.go.jp \\ ${ }^{2}$ Shinjo Branch of Snow and Ice Research Center, National Research Institute for Earth Science and Disaster Prevention, \\ 1400 Tokamachi, Shinjo 996-0091, Japan
}

\begin{abstract}
Meteorological data from mountainous areas of Japan have been collected by the National Research Institute for Earth Science and Disaster Prevention (NIED) for almost 20 years. The collected long-period data indicate that neither a notable increase in mean winter temperature nor a reduction in snow depth has occurred in these areas. The maximum snow depth, $\mathrm{SD}_{\text {max }}$ and maximum snow water equivalent, $\mathrm{SWE}_{\max }$, show similar fluctuation trends, although with large year-to-year variations in value and a larger fluctuation range for $\mathrm{SWE}_{\max }$ than for $\mathrm{SD}_{\max }$. This result suggests that monitoring of only $\mathrm{SD}_{\max }$ in mountainous areas is not sufficient for understanding the quantitative fluctuation of water resources originating from snow. The $\mathrm{SD}_{\max }$ fluctuation trends in mountainous areas sometimes differ from those in flatland areas because mountain $\mathrm{SD}_{\max }$ depends more on winter precipitation than on mean winter air temperature, whereas the opposite is true for flatlands. In addition, the dependence ratio of $\mathrm{SD}_{\max }$ on fluctuations in winter precipitation changes with altitude because the distributions of precipitation with air temperature change with altitude.
\end{abstract}

\section{INTRODUCTION}

It is reported that seasonal snow-cover area in the Northern Hemisphere has decreased and that the length of the snowcover season has also decreased when compared with that in the 1970s (e.g. Rikiishi and others, 2004). These trends are considered to result from the recent global warming and are clearer in the middle latitudes. Japan is located on the east side of the Eurasian continent and mainly consists of two large islands, Honshu and Hokkaido. In winter, strong northwesterly monsoons blow from Siberia to the islands of Japan, and the monsoons, collecting large amounts of vapor while passing over the warm Sea of Japan, hit the backbone mountains of Japan and bring heavy snowfall to the northwestern part of the mountains. Therefore, the areas facing the Sea of Japan have some of the world's deepest seasonal snowpacks.

Japan's mountainous areas are located at relatively low latitudes $\left(35-45^{\circ} \mathrm{N}\right)$ in a warm temperate zone, so even slight climate changes are likely to affect snow conditions. In fact, the simulation results based on predicted data using the coupled ocean-atmosphere global climate model indicate that snow depth in the Honshu region will decrease considerably by 2090 (Inoue and Yokohama, 2003). On the other hand, a recent study implied the possibility that the decrease in Arctic sea-ice cover could cause colder winters in the Eurasian continent (Honda and others, 2009). Indeed, during the winter of 2006 (the winter season of 2005/06 is designated as 2006; hereafter, the same rule is applied when allocating year to the winter seasons), Japan experienced anomalously low temperature and heavy snowfall (e.g. Takano and others, 2008). Therefore, the reaction of snow cover in Japan to global warming is complicated and remains a matter warranting further investigation.

With respect to water resources, it is important to understand the fluctuations of mountain snow conditions because snow meltwater provides a valuable water resource. Until recently, however, few continuously operating meteorological sites have existed in the Japanese mountains due to severe weather conditions. Matsuura and others (2005) analyzed 11 years' worth of data collected from 1989 to 1999 at Busuno (567 m a.s.l.) in the middle of Honshu, facing the Sea of Japan. They found no notable rise in mean wintertime air temperature and no obvious trend in changes in precipitation in that mountainous area. Their study is very useful for providing a preliminary understanding of fluctuation in a snowy environment at relatively high altitude. However, their data were obtained in only one region at an elevation that may be slightly too low to regard the station as a mountain observation site. Therefore, it is still useful to examine recent fluctuations in snowy environments throughout Japanese mountainous areas as a whole.

About 20 years ago, the National Research Institute for Earth Science and Disaster Prevention (NIED) constructed a Snow and Weather observation Network (SW-Net) in mountainous areas of Japan to measure meteorological and snow conditions (Nakamura and others, 1997; Shimizu and Abe, 2001). The primary aim of SW-Net is to obtain basic meteorological information for use in preventing snow disasters in mountain areas. However, the long-term data record is also useful for investigating the sensitivity of snowpack properties to climate change, particularly to global warming.

Using SW-Net data up to winter 2005, Yamaguchi and others (2007) showed the features of snowy environments in Japanese mountainous regions. In this paper, we present the newest data, including those for heavy-snowfall winters (2005, 2006) and anomalously warm winters (2007, 2009), and discuss the fluctuations in snowy mountain environments. In this study, we define the winter season as the period 1 December-31 March. 


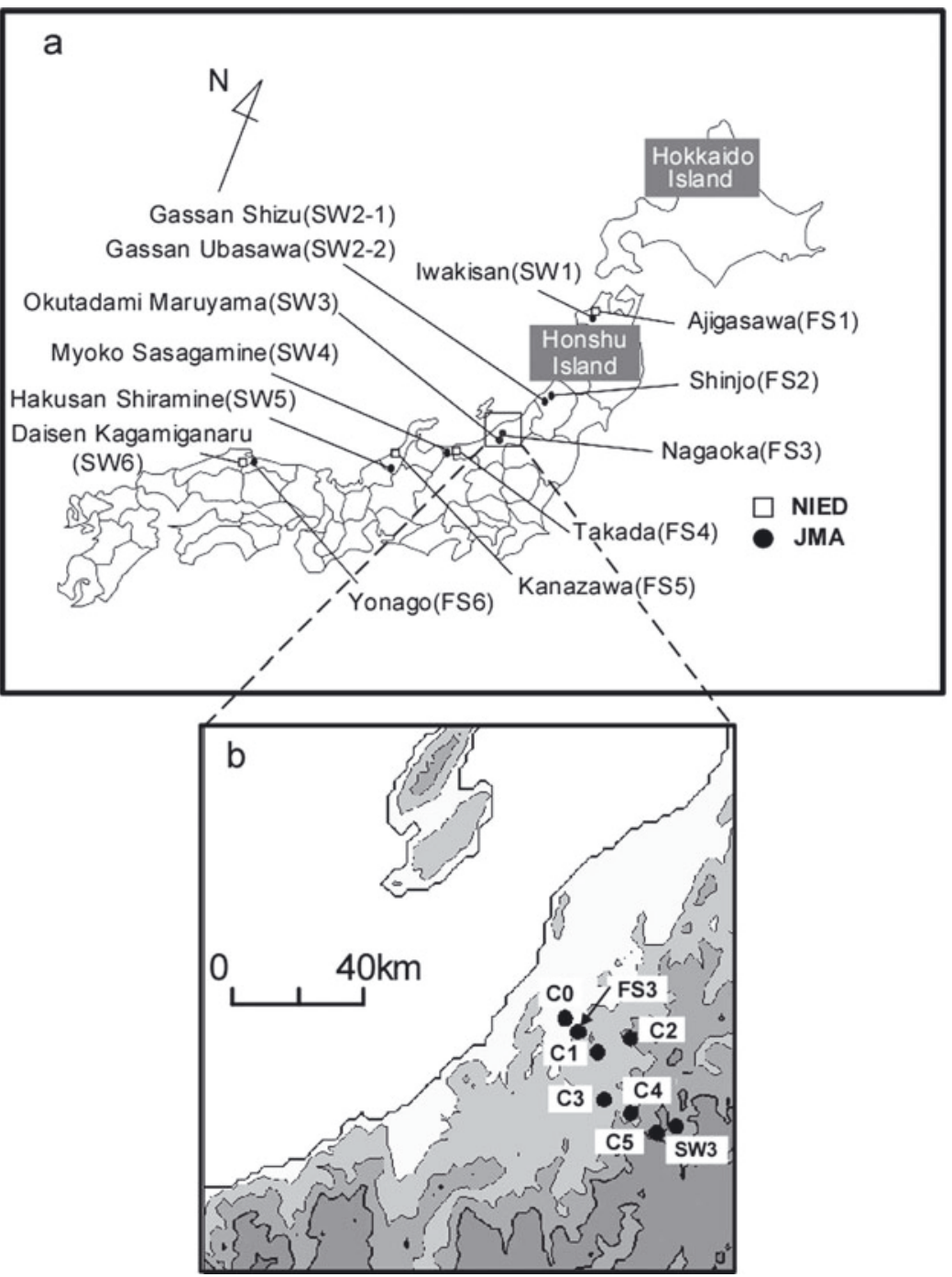

Fig. 1. Locations of the observation sites: (a) SW-Net, (b) C-Net.

\section{OBSERVATION SITES}

The observation stations established by the NIED are located on six mountains, which are considered to have the largest snowpack in each area (Fig. 1a). The SW-Net, composed of these mountain stations, covers all snowy mountainous areas of Japan from $35^{\circ} \mathrm{N}$ to $43^{\circ} \mathrm{N}$ at $<2^{\circ}$ intervals. The basic measurement elements at all sites are air temperature measured using PT-100 type thermometers, snow depth determined using ultrasonic/laser snow-depth gauges, and snow mass (snow water equivalent) measured by metal wafers consisting of a pressure-sensing plate filled with antifreeze solution (Kimura, 1983). A number of sites also collect precipitation data measured using a tipping-bucket rain/snow gauge, which has a heater and a windshield to better capture snow, and wind-direction and -speed data measured using an anemometer.

Each SW-Net site is paired with a nearby flatland site for comparison of both snowy environments. The flatland sites are operated by the Japan Meteorological Agency (JMA) and record air temperature, precipitation and snow depth. In addition to these meteorological elements, two NIED sites have recorded long-term and detailed data on snow conditions, including snow mass, daily snowfall and snowcover structure (Fig. 1a).
In addition to the SW-Net, NIED established another network (C-Net) distributed throughout one of the heaviestsnowfall regions of Honshu island (Fig. 1b). The main aim of C-Net is to provide detailed information on the altitudinal distribution of snow depth to prevent snow disasters in the region; thus, only snow depth has been measured at C-Net sites since 1998. Table 1 describes the location and elevation of the sites in both networks.

\section{FLUCTUATIONS OF SNOWY CONDITIONS IN MOUNTAINOUS AREAS}

Figures 2 and 3 present variations in snow conditions at each SW-Net site in the northern and southern parts of the network, respectively. In addition to data from mountain sites, data from two low-altitude sites (FS2 and FS3) are also shown as representative of flatland sites in northern (FS2) and southern (FS3) areas. Compared with Figure 3, Figure 2 shows a larger number of missing data because of measurement difficulties at mountain sites, where climate conditions are more severe than in the southern part of the network.

First, we discuss the fluctuations in mean air temperature, $T$, over the winter season in SW-Net. The large variations in interannual $T$ fluctuation at each site shown in Figures $2 \mathrm{a}$ 
Table 1. Locations of the SW-Net and C-Net observation sites

\begin{tabular}{|c|c|c|c|c|c|}
\hline \multirow{2}{*}{\multicolumn{2}{|c|}{ Site }} & \multirow[t]{2}{*}{ Location } & \multirow{2}{*}{$\begin{array}{c}\text { Horizontal } \\
\text { separation* } \\
\text { km }\end{array}$} & \multirow{2}{*}{$\begin{array}{l}\text { Altitude } \\
\text { ma.s.l. }\end{array}$} & \multirow{2}{*}{$\begin{array}{c}\text { Altitude } \\
\text { separation* } \\
\text { m }\end{array}$} \\
\hline & & & & & \\
\hline \multicolumn{6}{|c|}{ SW-Net } \\
\hline \multirow[t]{2}{*}{ Pair 1} & SW1 & $40^{\circ} 39^{\prime} \mathrm{N}, 140^{\circ} 18^{\prime} \mathrm{E}$ & 17 & 1238 & 1198 \\
\hline & $\mathrm{FS}^{\dagger}$ & $40^{\circ} 47^{\prime} \mathrm{N}, 140^{\circ} 12^{\prime} \mathrm{E}$ & & 40 & \\
\hline \multirow{3}{*}{ Pair 2} & SW2-1 & $38^{\circ} 29^{\prime} \mathrm{N}, 140^{\circ} 00^{\prime} \mathrm{E}$ & 43 & 710 & 583 \\
\hline & $(S W 2-2)^{*}$ & $\left(38^{\circ} 31^{\prime} \mathrm{N}, 140^{\circ} 00^{\prime} \mathrm{E}\right)$ & & (1150) & \\
\hline & FS2 & $38^{\circ} 47^{\prime} \mathrm{N}, 140^{\circ} 19^{\prime} \mathrm{E}$ & & 127 & \\
\hline \multirow[t]{2}{*}{ Pair 3} & SW3 & $37^{\circ} 10^{\prime} \mathrm{N}, 139^{\circ} 13^{\prime} \mathrm{E}$ & 42 & 1205 & 1108 \\
\hline & FS3 & $37^{\circ} 26^{\prime} \mathrm{N}, 138^{\circ} 53^{\prime} \mathrm{E}$ & & 97 & \\
\hline \multirow[t]{2}{*}{ Pair 4} & SW4 & $36^{\circ} 52^{\prime} \mathrm{N}, 138^{\circ} 05^{\prime} \mathrm{E}$ & 31 & 1310 & 1297 \\
\hline & $\mathrm{FS} 4^{\dagger}$ & $36^{\circ} 06^{\prime} \mathrm{N}, 138^{\circ} 15^{\prime} \mathrm{E}$ & & 13 & \\
\hline \multirow{2}{*}{ Pair 5} & SW5 & $36^{\circ} 11^{\prime} \mathrm{N}, 136^{\circ} 38^{\prime} \mathrm{E}$ & 45 & 835 & 829 \\
\hline & $\mathrm{FS}^{\dagger}$ & $37^{\circ} 35^{\prime} \mathrm{N}, 136^{\circ} 38^{\prime} \mathrm{E}$ & & 6 & \\
\hline \multirow[t]{2}{*}{ Pair 6} & SW6 & $35^{\circ} 20^{\prime} \mathrm{N}, 133^{\circ} 35^{\prime} \mathrm{E}$ & 17 & 875 & 869 \\
\hline & $\mathrm{FS}^{\dagger}$ & $35^{\circ} 26^{\prime} \mathrm{N}, 133^{\circ} 20^{\prime} \mathrm{E}$ & & 6 & \\
\hline \multirow[t]{2}{*}{ Site } & & Location & $\begin{array}{l}\text { Horizontal } \\
\text { separation }^{\S}\end{array}$ & Altitude & $\begin{array}{c}\text { Altitude } \\
\text { separation }^{\S}\end{array}$ \\
\hline & & & $\mathrm{km}$ & ma.s.l. & $\mathrm{m}$ \\
\hline \multicolumn{6}{|l|}{ C-Net } \\
\hline $\mathrm{CO}^{\dagger}$ & & $37^{\circ} 27^{\prime} \mathrm{N}, 138^{\circ} 49^{\prime} \mathrm{E}$ & 7 & 23 & -74 \\
\hline $\mathrm{C} 1$ & & $37^{\circ} 22^{\prime} \mathrm{N}, 138^{\circ} 57^{\prime} \mathrm{E}$ & 8 & 423 & -326 \\
\hline $\mathrm{C} 2$ & & $37^{\circ} 24^{\prime} \mathrm{N}, 139^{\circ} 04^{\prime} \mathrm{E}$ & 17 & 510 & 413 \\
\hline C3 & & $37^{\circ} 13^{\prime} \mathrm{N}, 138^{\circ} 14^{\prime} \mathrm{E}$ & 22 & 110 & 13 \\
\hline $\mathrm{C} 4$ & & $37^{\circ} 11^{\prime} \mathrm{N}, 139^{\circ} 05^{\prime} \mathrm{E}$ & 31 & 293 & 196 \\
\hline C5 & & $37^{\circ} 09^{\prime} \mathrm{N}, 139^{\circ} 09^{\prime} \mathrm{E}$ & 39 & 769 & 672 \\
\hline
\end{tabular}

*Between mountain and flatland site.

${ }^{\dagger}$ Station of the Japan Meteorological Agency.

\$SW2-2 was established in 2002

${ }^{\S}$ Between each station and FS3.

and $3 \mathrm{a}$ are similar to the peaks that occurred in 1995, 1998, 2004 and 2007. The same trend is seen for flatland sites (FS2 and FS3). However, detailed examination reveals somewhat different trends between Figures $2 \mathrm{a}$ and $3 \mathrm{a}$. For example, the $T$ values in Figure 3a show a peak in 2009 that is almost the same as the high values in 2007; however, the $T$ values in Figure 2a do not show a remarkable peak in 2009, even though $T$ was slightly higher in 2009 than in 2008. The average (standard deviation) values over the period 19952010 are $-8.0 \pm 0.6^{\circ} \mathrm{C}$ at SW1, $-2.0 \pm 0.9^{\circ} \mathrm{C}$ at SW2-1, $-3.8 \pm 0.7^{\circ} \mathrm{C}$ at SW3, $-3.8 \pm 0.8^{\circ} \mathrm{C}$ at SW $4,-0.1 \pm 0.8^{\circ} \mathrm{C}$ at SW5, and $-0.2 \pm 0.7^{\circ} \mathrm{C}$ at SW6 for mountainous areas and $+0.2 \pm 0.5^{\circ} \mathrm{C}$ at FS2 and $+2.7 \pm 0.7^{\circ} \mathrm{C}$ at FS3 for flatland areas. Although the average temperature varied from site to site, the standard deviations of each site are of the same order, including for the flatland sites, and no notable increases in mean winter air temperature were found at any of the sites during the observation period.

Second, we discuss the fluctuations in maximum snow depth, $\mathrm{SD}_{\max }$ in $\mathrm{SW}-\mathrm{Net}$. The maximum value of $\mathrm{SD}_{\max }$ in all measurement data was $771 \mathrm{~cm}$, measured at SW2-2 in 2003 (Fig. 2a). Data have been collected at SW2-2 since then, and the 2003 conditions do not seem to be very different from those in other years. In fact, $\mathrm{SD}_{\max }$ at SW2-2 exceeded $700 \mathrm{~cm}$ in three of the six winters in which measurements were taken. Therefore, in mountainous areas around SW2-2, SD $D_{\max }$ must normally accumulate to
Table 2. Correlations of maximum snow depth between mountain sites and adjacent flatland sites

Sample No. Correlation coefficient

\begin{tabular}{lrl}
\hline Pair 1 & 6 & 0.87 \\
Pair 2 & 13 & 0.89 \\
Pair 3 & 21 & 0.48 \\
Pair 4 & 20 & 0.47 \\
Pair 5 & 15 & 0.44 \\
Pair 6 & 15 & 0.39 \\
\hline
\end{tabular}

$\sim 700 \mathrm{~cm}$. The large trends seen in interannual fluctuation in $\mathrm{SD}_{\max }$ at each site are similar, in that they have two peaks: one in 1996 and the other in 2000. Additional low values are shown in 1998 and 2007. Several studies (e.g. Ishizaka, 2004) have reported that $\mathrm{SD}_{\max }$ in flat areas of Japan decreased dramatically at the start of the 1990s, but unfortunately our mountain-site data have been gathered only since the 1990s. Therefore, we did not mention the snowy environments in mountain areas before the 1990s, but our data show no notable reduction in $\mathrm{SD}_{\max }$ over at least the past 20 years. A detailed examination of the trends of interannual fluctuation at each site revealed some differences. For example, SW4 and SW5 had conspicuous peaks in 2006, when heavy snowfall also occurred in flatland areas (e.g. lyobe and others, 2007), while other sites had no such peaks. In addition, in winter 2007, which was the warmest winter in $>100$ years in Japan, $\mathrm{SD}_{\max }$ data from most of SW-Net showed the minimum values among the measurement periods, but SD max $_{\text {ax }}$ at SW2-1, SW2-2 and SW3 did not show minimum values, although the $\mathrm{SD}_{\max }$ values became smaller than those of the previous year.

To better understand the differences between snowy environments in the mountains and in the flatland areas, we calculated the correlation coefficients between the $\mathrm{SD}_{\max }$ of mountain and nearby flatland sites. The results are summarized in Table 2. Here we consider that there is a statistically significant correlation between a pair of datasets if the correlation coefficient, $R$, is larger than the value of $R$ calculated from a $t$ test with levels of significance of $5 \%$. Pairs 1-4 showed a statistically significant score. In particular, pairs 1 and 2 in northern Honshu showed a strong correlation, i.e. the values of $R$ at both sites are larger than the value of $R$ calculated from a $t$ test with levels of significance of $1 \%$. On the other hand, a significant statistical correlation was not found for the western pairs (pairs 5 and 6), i.e. the values of $R$ at these two sites are smaller than the value of $R$ calculated from $t$ tests with levels of significance of $5 \%$. These results suggest that the fluctuations in snowy mountain environments sometimes differ from those in flat parts of the same regions, and moreover, it is difficult to estimate the correct fluctuations in snow cover in mountainous areas based on that of nearby flatland areas, especially in western parts of Honshu.

Figures $2 \mathrm{c}$ and $3 \mathrm{c}$ show fluctuations in the maximum snow water equivalent, $S W E_{\max }$ at $\mathrm{SW}-\mathrm{Net}$ stations. The $\mathrm{SWE}_{\max }$ fluctuations generally correspond with those of $\mathrm{SD}_{\max }$, but the days of $\mathrm{SD}_{\max }$ usually do not correspond with days of $S W E_{\max }$. Yamaguchi and Abe (2007) analyzed a long period of SW-Net data and showed that the day of $\mathrm{SD}_{\max }$ was $\sim 1$ month earlier than that of $\mathrm{SWE}_{\max }$ in a normal year. 

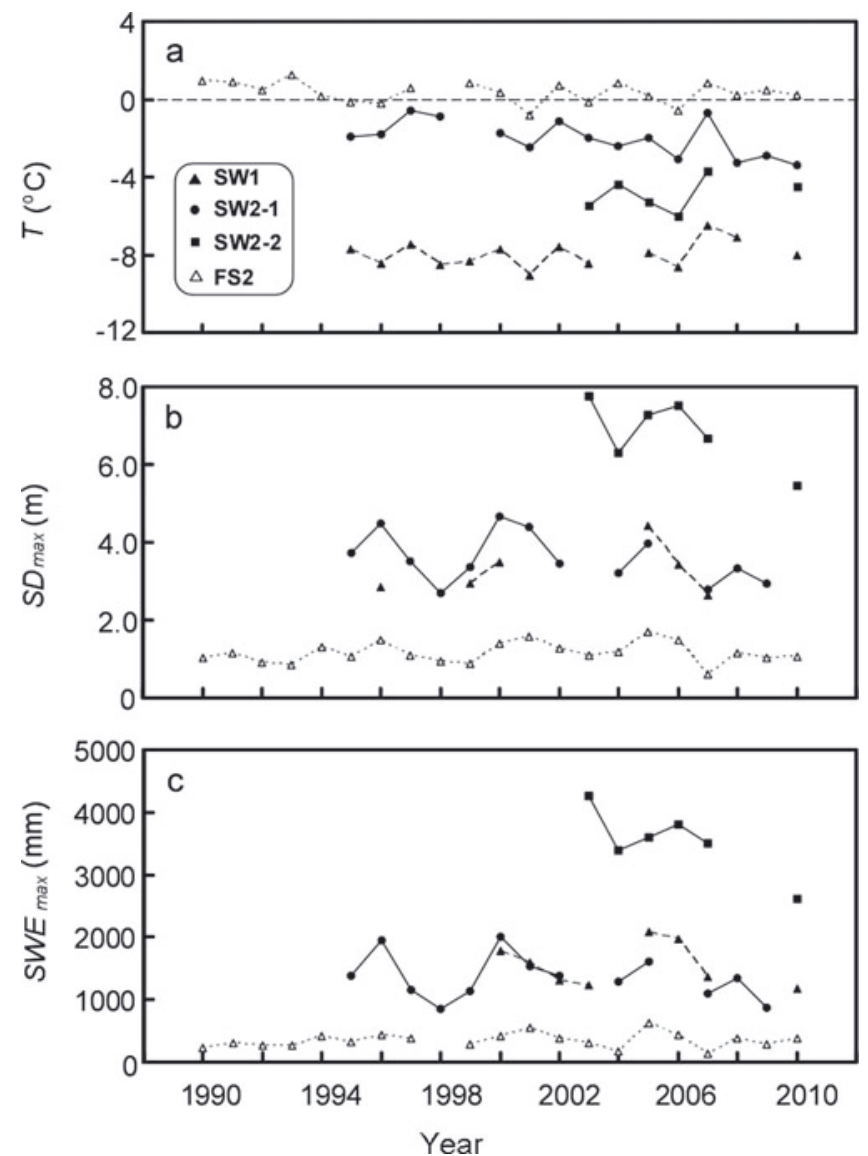

Fig. 2. Snowy conditions in the northern part of SW-Net. (a) Fluctuations in mean air temperature, $T$, over the winter season. (b) Fluctuations in maximum snow depth, $\mathrm{SD}_{\max }$ in the winter season. (c) Fluctuations in maximum water equivalent of snow, $\mathrm{SWE}_{\max }$, in the winter season.

We compared the change range of fluctuation of $\mathrm{SD}_{\max }$ with that of SWE $E_{\max }$ at five sites (SW2-2, SW3, SW4, SW5 and SW6) having $>10$ years of data (Table 3). Here we defined the change range $(C R)$ as the difference ratio between the average value and maximum (minimum) value during the data collection period. At all sites the values of CR were larger for $\mathrm{SWE}_{\max }$ than for $\mathrm{SD}_{\max }$ although the ratios varied from site to site. This result implies that water resources from snow, namely $\mathrm{SWE}_{\max }$ in mountainous areas may have a larger year-to-year change range than does $\mathrm{SD}_{\max }$
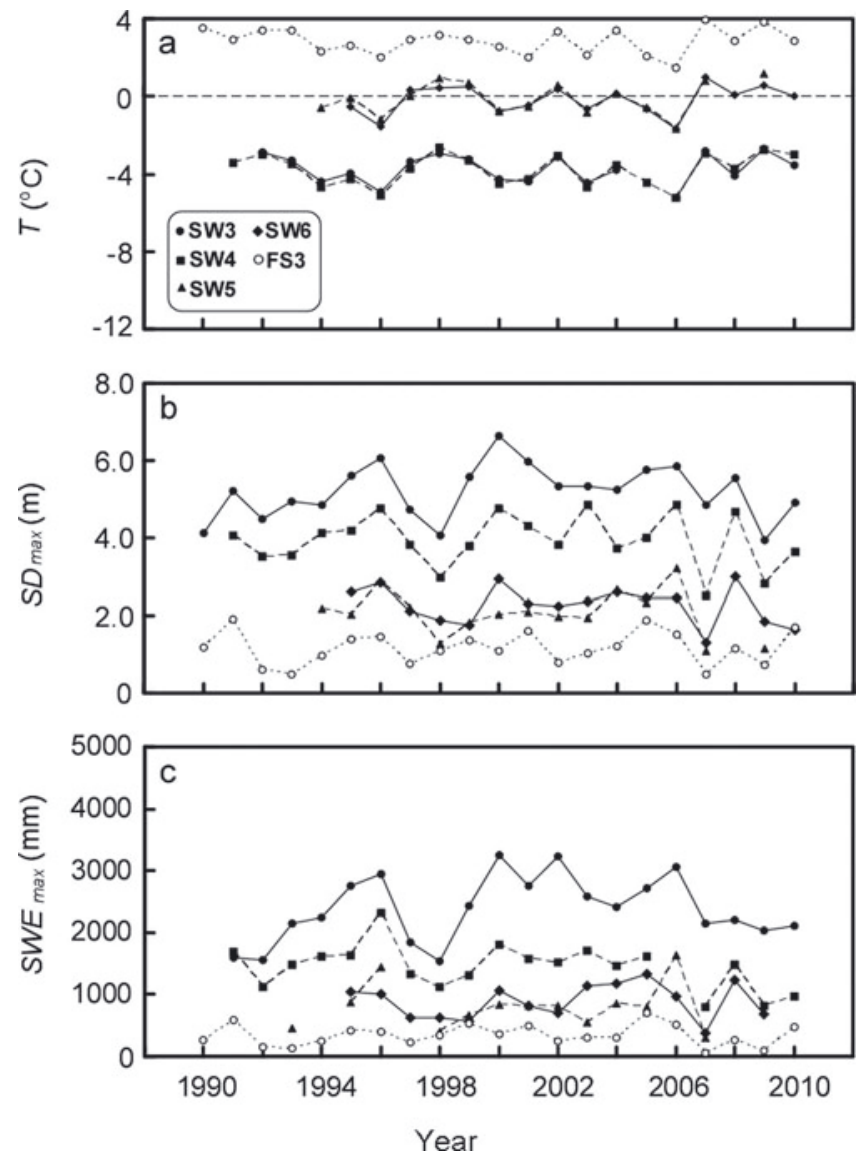

Fig. 3. Same as Figure 2, but for the southern part of SW-Net.

fluctuation, even though only $\mathrm{SD}_{\max }$ fluctuations are usually discussed in the context of changes in mountainous snowy conditions, because of the lack of $S W E_{\max }$ data.

Figure 4 shows the relationship between $\mathrm{SD}_{\max }$ and $S W E_{\max }$, which appears to change with the value of $\mathrm{SD}_{\max }$. That is, the average density over all snow depths, $\rho_{\text {ave, }}$ which was calculated by dividing $\mathrm{SWE}_{\max }$ by $\mathrm{SD}_{\max }$ increased with the increase in $\mathrm{SD}_{\max }$. The $\rho_{\text {ave }}$ values can be roughly classified into three groups, although $\rho_{\text {ave }}$ should change gradually with change of $\mathrm{SD}_{\max }$. In the first group, $\mathrm{SD}_{\max }$ is $<3.0 \mathrm{~m}$ and $\rho_{\text {ave }}$ is $\sim 300 \mathrm{~kg} \mathrm{~m}^{-3}$. In the second group, $\mathrm{SD}_{\max }$ is $3.0-5.0 \mathrm{~m}$ and $\rho_{\text {ave }}$ is $\sim 400 \mathrm{~kg} \mathrm{~m}^{-3}$. In the third group, $\mathrm{SD}_{\max }$ is $>5.0 \mathrm{~m}$ and $\rho_{\text {ave }}$ is $\sim 500 \mathrm{~kg} \mathrm{~m}^{-3}$. These results

Table 3. Amplitude of $\mathrm{SD}_{\max }$ and $S W E_{\max }$ at five sites

$\begin{array}{lllll} & \text { Site } & \\ \text { SW2-2 } & \text { SW3 } & \text { SW4 } & \text { SW5 } & \text { SW6 }\end{array}$

\section{$S D_{\text {max }}$}

Years of data

Average (m)

$\operatorname{Max}(\mathrm{m})$

$\operatorname{Min}(\mathrm{m})$

$S W E_{\text {max }}$

Years of data

Average (mm)

$\operatorname{Max}(\mathrm{mm})$

Min $(\mathrm{mm})$
13

3.6 (amplitude)

$4.7(+30 \%)$

$2.7(-25 \%)$

13

1358 (amplitude)

$2004(+48 \%)$

$850(-37 \%)$
21

5.5 (amplitude)

$6.6(+28 \%)$

$4.0(-24 \%)$

20

2577 (amplitude)

$3239(+37 \%)$

$1536(-35 \%)$
20

4.1 (amplitude)

$4.9(+23 \%)$

$2.5(-36 \%)$

19

1579 (amplitude)

$2317(+61 \%)$

$805(-44 \%)$
15

209 (amplitude)

$3.2(+60 \%)$

$1.1(-47 \%)$

13

807 (amplitude)

1638 (+104\%)

$310(-61 \%)$
16

2.4 (amplitude)

$3.0(+32 \%)$

$1.3(-43 \%)$

15

880 (amplitude)

$1330(+49 \%)$

$389(-56 \%)$ 


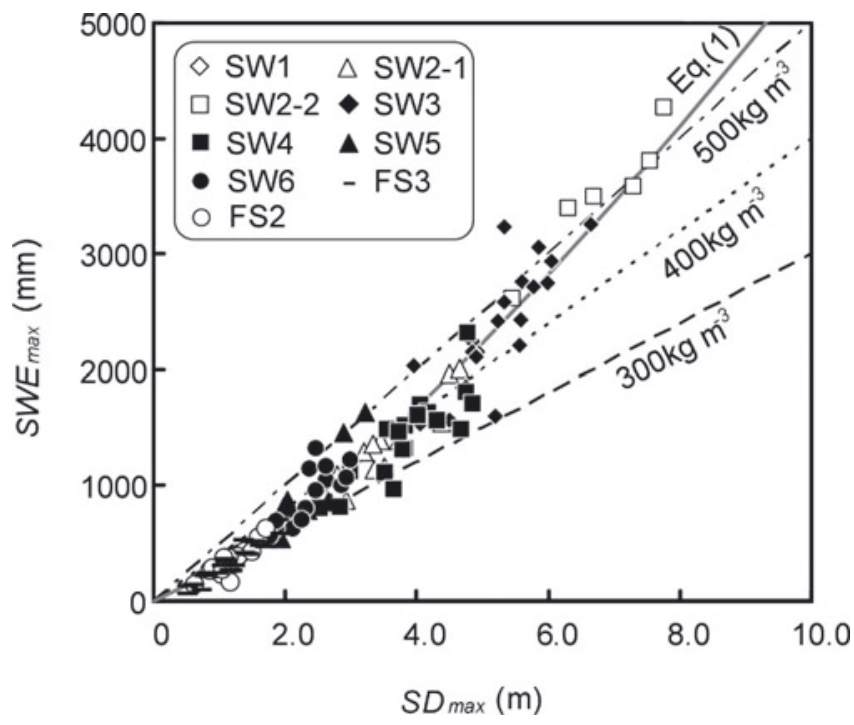

Fig. 4. Relationship between maximum snow depth, $\mathrm{SD}_{\max }$ and maximum water equivalent of snow, $\mathrm{SWE}_{\max }$. Dashed lines indicate the density averaged over the snow depth, $\rho_{\text {ave, }}$ with values given under each line. Gray line indicates the regression curve calculated from Equation (1).

indicate that the $\rho_{\text {ave }}$ values obtained at the flatland site cannot be directly applied to estimate $\mathrm{SWE}_{\max }$ in mountainous areas. To connect the relationship between $\mathrm{SD}_{\max }$ and $\mathrm{SWE}_{\max }$ more smoothly, we introduce the $n$ th-power function to describe the relationship between these values, resulting in the following equation:

$$
\mathrm{SWE}_{\max }=272 \times \mathrm{SD}_{\max }^{1.3}(R=0.98),
$$

where $R$ is the correlation coefficient. The equation implies the amplitude of $\mathrm{SWE}_{\max }$ fluctuation is larger than that of $\mathrm{SD}_{\max }$ because the value of $n$ in Equation (1) is $>1.0$.

\section{ALTITUDINAL DISTRIBUTIONS OF MAXIMUM SNOW DEPTH IN C-NET}

As described above, the interannual fluctuations in $\mathrm{SD}_{\max }$ sometimes differed between mountain sites and nearby flatland sites. To examine this finding in detail, we analyzed $\mathrm{SD}_{\max }$ data measured at several sites (C-Net), each located at a different altitude within a small local region (Fig. 1b).

Data on snowfall amounts at each site are useful for discussing the altitudinal fluctuation in snow depth. However, snowfall data were not collected in C-Net except at FS3. The interannual fluctuation in snowfall should mainly result from two fluctuations: fluctuations in the amount of winter precipitation and fluctuations in the percentage of winter precipitation falling as snow. Hence, we adopted the following two parameters: winter precipitation, $P$, at FS3, which was used as a representative value for this area, and the altitude, $H_{T 1}$, at which the mean winter air temperature was $1{ }^{\circ} \mathrm{C}$, which was used to estimate the snow percentage of winter precipitation; it can be assumed that snow is the dominant form of winter precipitation at altitudes higher than $H_{T 1}$. We calculated the lapse rate for each winter using data at FS3 and SW3, and determined $H_{T 1}$ based on the lapse rate for each winter. We additionally show the cumulative measured snowfall depth during the winter season, NS, at FS3 as a reference for actual snowfall.
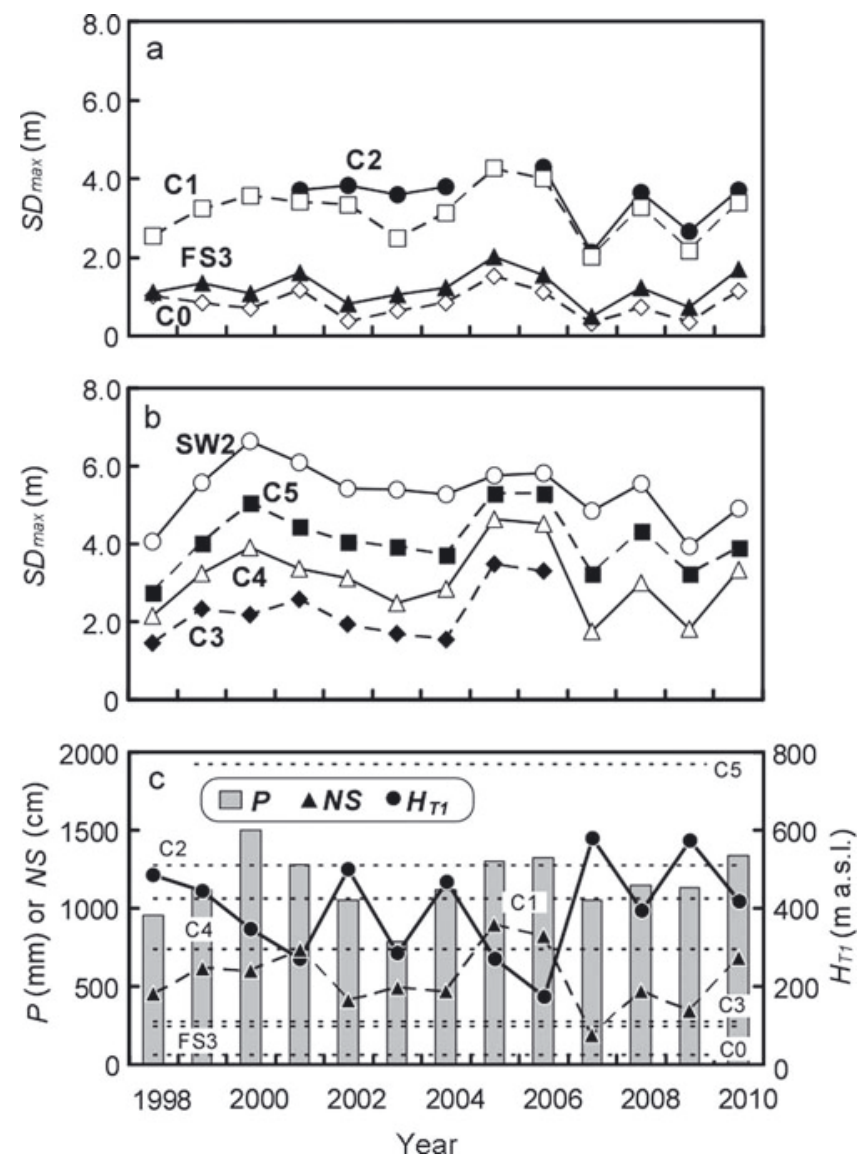

Fig. 5. Maximum snow depth at C-Net and meteorological factors. $(\mathrm{a}, \mathrm{b})$ Fluctuations in maximum snow depth, $\mathrm{SD}_{\max }$ at each site. (c) Fluctuations in $H_{T 1}$ and total winter precipitation, $P$, and cumulative depth of snowfall, NS, during the winter season at FS3. The dashed lines indicate the altitude of each site.

Variations in $\mathrm{SD}_{\max }$ at each site are presented in Figure 5a and $b$. Each interannual fluctuation in $\mathrm{SD}_{\max }$ seems to be almost similar, but there are four considerable differences.

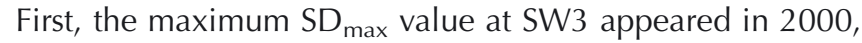
but that at other sites mostly appeared in 2005, with some higher-altitude sites having a peak in 2000. Second, the minimum $\mathrm{SD}_{\max }$ values of the observation period appeared in 1998 at C5 and SW3, but in 2007 at other sites, although $\mathrm{SD}_{\max }$ was small at all sites in both years. Third, $\mathrm{SD}_{\max }$ values in 2001 were higher than those in 2000 at C0, FS3 and C3 (the relatively lower sites), but the other sites showed an opposite trend. Fourth, $\mathrm{SD}_{\max }$ values showed an increase in 2003 at C0 and FS3, whereas the opposite was found at other sites. Next, we examine these four cases in more detail.

In 2000, $H_{T 1}$ was located near the average altitude (373 m a.s.l.), and $P$ was largest during the observation period ( $\sim 1.3$ times greater than the average year). Therefore, the higher-altitude sites, especially SW3, may have received huge snowfall amounts as a result of large $P$, resulting in the clear peak in 2000. Moreover, the difference between $\mathrm{SD}_{\max }$ in 1999 and that in 2000 shows altitudinal dependence, namely, the difference increases with altitude. On the other hand, the lower sites may not have experienced such a strong effect of the $P$ fluctuation due to the normal temperature conditions. In fact, NS was almost the same in 2000 as in 1999 even though $P$ was larger in 2000 than in 1999.

In 1998, because $H_{T 1}$ was located at a higher position (486 ma.s.l.), sites lower than $H_{T 1}$ should have had less 

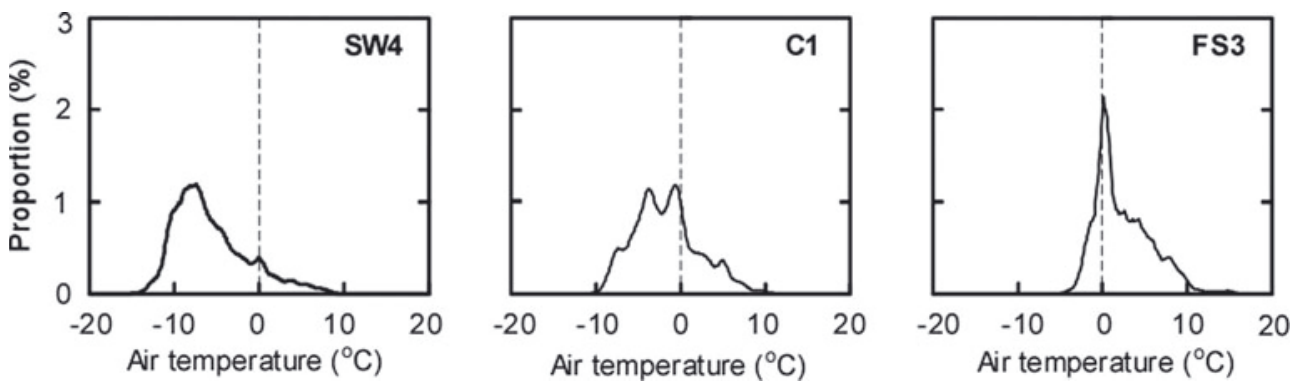

Fig. 6. Winter precipitation curves averaged over 5 years at each site. The sum of the precipitation amount for each temperature was normalized by dividing by the total precipitation for the winter season. The graphs show running mean values for 11 data points.

snowfall. Indeed, NS in 1998 was small. In addition, $P$ in 1998 was smaller than average. Thus, sites higher than $H_{T 1}$ also likely received smaller amounts of snowfall because of the small precipitation in that year. On the other hand, $H_{T 1}$ in 2007 was located at its highest position (600 ma.s.l.). Therefore, most of the sites except C5 and SW3 (which were higher than $H_{T 1}$ ) may have had less snowfall than usual because of the higher temperature. In fact, NS in 2007 was the smallest during the observation period, even though $P$ in 2007 was almost the same as the average value, suggesting that higher sites could have had normal snowfall amounts. For these reasons, the timing of minimum $\mathrm{SD}_{\max }$ differed between high-altitude sites (C5 and SW3) and other sites.

In 2001, $H_{T 1}$ was at a lower altitude than in 2000 , but $P$ was less in 2001 than in 2000. Therefore, no large increase in $\mathrm{SD}_{\max }$ occurred at higher sites. On the other hand, snow could be expected to make up a large percentage of total winter precipitation at lower sites because $H_{T 1}$ was lower than average. Indeed, NS was larger in 2001 than in 2000, although $P$ was smaller in 2001 than in 2000.

In 2003, both $H_{T 1}$ and $P$ were lower than average. Therefore, snowfall amounts may have been smaller than average at higher sites due to reduced precipitation, but above average at lower sites because of lower temperature. In fact, NS was slightly larger in 2003 than in 2002.

As demonstrated above, the $T$ condition is a dominant factor in $\mathrm{SD}_{\max }$ at lower sites, whereas $\mathrm{SD}_{\max }$ at higher sites has a stronger connection with the $P$ condition. The dependence of $\mathrm{SD}_{\max }$ on $P$ should increase with altitude because the fluctuation of $T$ does not have a large influence on the percentage of snow in winter precipitation if high altitude makes $T$ low enough for snow formation.

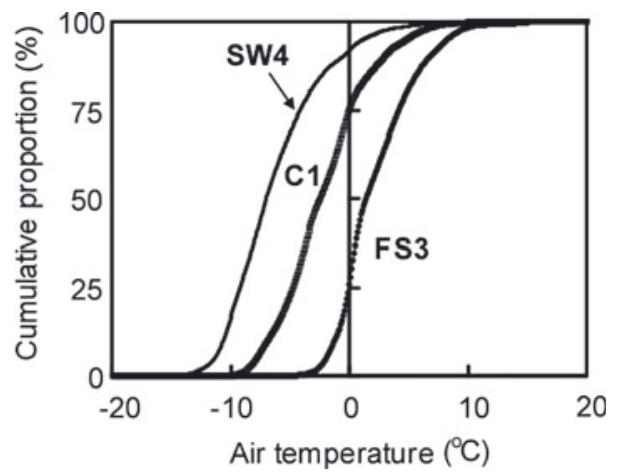

Fig. 7. Cumulative proportion curves of winter precipitation at each site, calculated from Figure 6.
To examine this hypothesis, we analyzed the relationship between air temperature and precipitation at three sites with different altitudes: FS3 (97 ma.s.l.) representing the flatland area, C1 (423 m a.s.I.) representing the mid-altitude area and SW4 (1305 ma.s.I.) representing the mountainous area. Note that SW4 was located in a different region from the other two sites, but the mountain site in the same region (SW3) could not be used because it did not collect precipitation data. Figure 6 shows the distributions of precipitation with air temperature during each precipitation event; the curves in the figure show the normalized form obtained from averaged data over 5 years. In the figure, the resolution of air temperature is $0.1^{\circ} \mathrm{C}$, and the sum of precipitation at each temperature is a normalized value obtained by dividing by total precipitation in the winter season. Hereafter, we call this distribution the winter precipitation curve (WPC). The WPC at flatland site FS3 had a sharp peak near $0^{\circ} \mathrm{C}$, indicating that precipitation was most likely at a temperature of near $0^{\circ} \mathrm{C}$. At the mid-altitude site $\mathrm{C} 1$, there were two peaks, one around $0^{\circ} \mathrm{C}$ and the other around $-4^{\circ} \mathrm{C}$, but neither was as sharp as the peak at FS3. WPC at the mountain site SW4 also showed two peaks. The peak located near $0^{\circ} \mathrm{C}$ is very small, whereas the other located around $-8^{\circ} \mathrm{C}$ was large but not as sharp as that at FS3. The analysis results suggest that WPC changes with altitude, but that all the sites also have a WPC peak around $0^{\circ} \mathrm{C}$. These different patterns should affect the sensitivity of snowfall amount to fluctuation of air temperature.

Figure 7 shows the cumulative proportion curves, which were made from Figure 6 . Assuming that the critical air temperature between snow and rain is $1{ }^{\circ} \mathrm{C}$, we estimated the change in snow proportion, SP, with fluctuations in air temperature, $T$, of $\pm 0.7^{\circ} \mathrm{C}$, which was the standard deviation of air temperature during the period 1998-2010. The values of SP in an average year at each site were 44\% (FS3), 78\% (C1) and $91 \%$ (SW4). If $T$ was decreased by $0.7^{\circ} \mathrm{C}$, the SP changed to $51 \%$ (FS3), 81\% (C1) and 93\% (SW4). On the other hand, if $T$ was increased by $0.7^{\circ} \mathrm{C}$, the SP values changed to $32 \%$ (FS3), 73\% (C1) and 89\% (SW4). Therefore, SP at FS3 should fluctuate from $32 \%$ to $51 \%$; in other words, it should show a change range of $19 \%$ resulting from fluctuation in $T\left(\mathrm{CR}_{T}\right)$. At $\mathrm{C} 1$ and SW4, the $\mathrm{CR}_{T}$ values were $8 \%$ and $4 \%$, respectively. The standard deviation of $P$ during the period $1998-2010$ was $\pm 15 \%$. Thus, the fluctuation of SP caused by the fluctuation of $P\left(\mathrm{CR}_{P}\right)$ may be considered as $30 \%$. Comparing $\mathrm{CR}_{T}$ and $\mathrm{CR}_{P}, \mathrm{CR}_{P}$ was larger than $\mathrm{CR}_{T}$ at all sites, but the difference between $\mathrm{CR}_{P}$ and $\mathrm{CR}_{T}$ increased with altitude. These results support our hypothesis, i.e. the dependence of $\mathrm{SD}_{\max }$ on $P$ should increase with altitude. 
In the above analyses, we assumed for simplicity that the fluctuation in $P$ is independent of that in $T$, but some studies (Nakamura and Shimizu, 1996; Takeuchi and others, 2008; Yamaguchi and others, 2009) have indicated that there is an obvious relationship between fluctuations in $P$ and $T$ in the study region. Therefore, the natural altitudinal distribution of $\mathrm{SD}_{\max }$ should show more complicated fluctuations than those estimated from the above hypothesis. However, our study should contribute to an understanding of the reasons behind observed altitudinal distribution of $\mathrm{SD}_{\max }$.

\section{CONCLUSIONS}

We collected and analyzed more than 15 years' worth of data on air temperature, snow depth and snow water equivalent in mountainous regions of Japan. In the mountainous areas, neither a notable increase in mean winter temperature nor a reduction of maximum snow depth, $\mathrm{SD}_{\text {max, }}$ was recognized.

Although the fluctuations in maximum snow water equivalent, $S W E_{\max }$, showed the same trend as $\mathrm{SD}_{\max }$, the $\mathrm{SWE}_{\max }$ fluctuation was larger than that of $\mathrm{SD}_{\max }$. Therefore, monitoring of only $\mathrm{SD}_{\max }$ fluctuations is not sufficient for revealing the fluctuation of water resource originating from snow.

To better understand the correlations between the variables, data from each mountain site were compared with those from a nearby flatland site. The $\mathrm{SD}_{\max }$ fluctuations in the mountainous areas sometimes showed different trends from those in flatland areas, especially the western parts of Honshu, because mountain $\mathrm{SD}_{\max }$ depends more on winter precipitation than on mean winter air temperature, whereas mean air temperature is the dominant factor influencing fluctuations in $\mathrm{SD}_{\max }$ in flatlands.

Although the data in this study cover more than 15 years, a longer study period is needed to clearly determine the effects of climate change on mountain snowpack. Thus, data from these sites will continue to be collected and analyzed.

\section{ACKNOWLEDGEMENTS}

We thank the JMA for providing the hourly meteorological datasets. We are also grateful for helpful suggestions from M. Ishizaka, T. Kobayashi, I. Kamiishi, H. Hirashima and H. Motoyoshi of the Snow and Ice Research Center, NIED, as well as from T. Sato, K. Kosugi and M. Nemoto of the Shinjo Branch of the Snow and Ice Research Center, NIED. Helpful comments and suggestions from R. Essery and an anonymous reviewer are greatly appreciated.

\section{REFERENCES}

Honda, M., J. Inoue and S. Yamane. 2009. Influence of low Arctic sea-ice minima on anomalously cold Eurasian winters. Geophys. Res. Lett., 36(8), L08707. (10.1029/2008GL037079.)

Inoue, S. and K. Yokohama. 2003. Estimates of snowfall depth, maximum snow depth, and snow pack environments under global warming in Japan from five sets of predicted data. J. Agr. Meteorol., 59(3), 227-236.

Ishizaka, M. 2004. Climatic response of snow depth to recent warmer winter seasons in heavy-snowfall areas in Japan. Ann. Glaciol., 38, 299-304.

Iyobe, T., K. Kawashima and K. Izumi. 2007. Characteristics of snow-depth distribution in Japan during heavy snowfall of 2005-2006 winter. Seppyo, J. Jpn. Soc. Snow/lce, 69(1). 45-52. [In Japanese with English summary.]

Kimura, T. 1983. Observation of water equivalent of snow cover by metal wafer. Rep. Natl Res. Cent. Disaster Prev. 31, 203-217. [In Japanese with English summary.]

Matsuura, S., K. Matsuyama, S. Asano, T. Okamoto and Y. Takeuchi. 2005. Fluctuation of the seasonal snowpack in a mountainous area of the heavy-snow district in the warm-temperate zone of Japan. J. Glaciol., 51(175), 547-554.

Nakamura, T. and M. Shimizu. 1996. Variation of snow, winter precipitation and winter air temperature during the last century at Nagaoka, Japan. J. Glaciol., 42(140), 136-140.

Nakamura, H., M. Shimizu, O. Abe, T. Kimura, M. Nakawo and T. Nakamura. 1997. A snow observation network for mountain area of NIED. In Izumi, M., T. Nakamura and R.L. Sack, eds. Snow engineering: recent advances. Rotterdam, A.A. Balkema, 539-541.

Rikiishi, K., E. Hashiya and M. Imai. 2004. Linear trends of the length of snow-cover season in the Northern Hemisphere as observed by the satellites in the period 1972-2000. Ann. Glaciol., 38, 229-237.

Shimizu, M. and O. Abe. 2001. Recent fluctuation of snow cover on mountainous areas in Japan. Ann. Glaciol., 32, 97-101.

Takano, Y., Y. Tachibana and K. Iwamoto. 2008. Influences of largescale atmospheric circulation and local sea surface temperature on convective activity over the Sea of Japan in December. SOLA, 4, 113-116.

Takeuchi, Y., Y. Endo and S. Murakami. 2008. High correlation between winter precipitation and air temperature in heavysnowfall areas in Japan. Ann. Glaciol., 49, 7-10.

Yamaguchi, S. and O. Abe. 2007. Characteristics of snow in Japanese mountainous regions during heavy snowfall in 2005/ 2006: data analyses over a long period. Seppyo, J. Jpn. Soc. Snow Ice, 69(1), 53-59. [In Japanese with English summary.]

Yamaguchi, S., O. Abe, S. Nakai and A. Sato. 2007. Recent snow cover fluctuations in the mountainous areas of Japan. IAHS Publ. 318 (Symposium at Foz do Iguaçu, Brazil - Glacier Mass Balance Changes and Meltwater Discharge), 116-125.

Yamaguchi, S., S. Nakai, K. Iwamoto and A. Sato. 2009. Influence of anomalous warmer winter upon statistics of measured winter precipitation data. J. Appl. Meteorol. Climatol., 48(11), 2403-2409. 